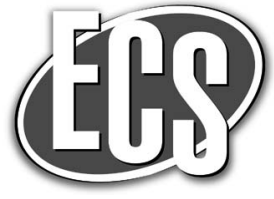

\title{
A Comparative Testing Study of Commercial 18650-Format Lithium-Ion Battery Cells
}

\author{
Valentin Muenzel, ${ }^{a, z}$ Anthony F. Hollenkamp, ${ }^{b}$ Anand I. Bhatt, ${ }^{\text {b,* }}$ Julian de Hoog, ${ }^{c}$ \\ Marcus Brazil, ${ }^{\mathrm{a}}$ Doreen A. Thomas, ${ }^{\mathrm{d}}$ and Iven Mareels ${ }^{\mathrm{a}}$ \\ ${ }^{a}$ Electrical and Electronic Engineering, University of Melbourne, Parkville, Melbourne, Victoria, Australia \\ ${ }^{b}$ Energy Flagship, Commonwealth Scientific and Industrial Research Organisation (CSIRO), Clayton, Melbourne, \\ Victoria, Australia \\ ${ }^{c}$ IBM Research - Australia, Melbourne, Victoria, Australia \\ ${ }^{d}$ Mechanical Engineering, University of Melbourne, Parkville, Melbourne, Victoria, Australia
}

\begin{abstract}
Demand for portable electronic and electrical devices has led to considerable growth in production of lithium-ion battery cells and the number of manufacturers thereof. However, due to lack of supplied information or independent verification, it is frequently difficult to compare cells based on available data. In this study, we conduct a comparative testing study on five types of 18650-format lithium-ion cells from three different commercial manufacturers, ranging from budget to high-performance cells. Key insights gathered in the comparison were that the tested budget cells frequently offer less than $20 \%$ of their rated capacity, that the budget cells degrade at a significantly higher proportional rate than other cells, and that certain high-performance cells exceed the size dimensions of the 18650 -format by over $3 \%$. Electrochemical impedance spectroscopy testing showed the budget cells to have internal impedances several times higher than other cells, leading to notably increased heat generation and a significantly reduced cell efficiency. Differential capacity analysis found this high internal resistance to notably impede lithium intercalation processes. The presented methodology is intended as a base framework for conducting subsequent comparative testing studies for Li-ion cells. (C) The Author(s) 2015. Published by ECS. This is an open access article distributed under the terms of the Creative Commons Attribution 4.0 License (CC BY, http://creativecommons.org/licenses/by/4.0/), which permits unrestricted reuse of the work in any medium, provided the original work is properly cited. [DOI: 10.1149/2.0721508jes] All rights reserved.
\end{abstract}

Manuscript submitted March 3, 2015; revised manuscript received May 13, 2015. Published May 28, 2015.

A strong demand for portable electronic and electrical devices in recent years has led to a corresponding demand for high-performance batteries. Due to the large amount of energy that can be stored per unit of weight and volume, lithium-ion (Li-ion) batteries have become the battery of choice for many small devices such as mobile phones, laptop computers and power tools. Increasingly these cells are also being used for much larger applications including electric bicycles, electric cars and stationary energy storage in domestic or commercial settings.

Li-ion battery cells first became commercially available in 1991 . Today, there are many different cell manufacturers that offer a wide variety of battery cells to both corporate and personal customers. Unfortunately however, reliable information on the physical dimensions and electrical characteristics can be difficult to obtain for many cells. High-end suppliers commonly provide data sheets that contain technical product information including factors such as size, weight, capacity, voltage profile and cycle life, as well as some limited measurement data to support these numbers. Low-cost products are frequently supplied only with a nominal capacity rating, without any measurement data. Where available, the ratings are typically based on in-house testing without independent verification. As private or small commercial consumers rarely have both the specific equipment and know-how required to accurately test cells, there is a risk that manufacturers may inflate ratings in order to make their products appear more competitive. This adds further complexity to the already difficult task of choosing cells for commercial or personal applications. As a result, there is scope for academic research to provide insight into the state-of-the-art of current commercial Li-ion battery cells.

When choosing batteries for use in applications, there are a wide variety of important battery characteristics that need to be considered.

Important physical characteristics of cells include the size, weight and shape. Commercial Li-ion batteries come in many shapes and sizes. ${ }^{1}$ The most common Li-ion battery format is called 18650 , which stands for a cylindrical cell with a diameter of $18 \mathrm{~mm}$ and a length of $65 \mathrm{~mm}$. While originally intended for use in laptops, the resulting economy of scale of 18650-format cells has led to adoption in other applications including many power tools, electric bicycles and Tesla Motors' electric cars. The widespread use, as well as the predefined format against which actual sizing can be compared, make 18650

${ }^{*}$ Electrochemical Society Active Member.

${ }^{\mathrm{z} E-m a i l: v . m u e n z e l @ s t u d e n t . u n i m e l b . e d u . a u ~}$ cells particularly interesting for study. For any application that offers flexibility regarding the shape of the battery, the physical parameters should be compared in direct correspondence with the electrical performance in order to select the cell or set of cells that offer the best trade-off between high capacity and charge and discharge capabilities and low weight and size while also taking into account the cost.

Important short-term electrical characteristics include maximum and minimum voltage limits, current capabilities, the capacity of the cell at the beginning of life for different charging and discharging rates and temperatures as well as the output voltage for different currents and states-of-charge. Table I summarizes findings of a range of initial capacity tests of 18650 cells published in the literature. The results show that the measured capacity of commercial 18650 cells can deviate somewhat from the nominal capacity. Note that the rate in the table is the C-rate, a normalized current parameter that is calculated by dividing the applied discharge current by the cell capacity. As an example, discharging a $1.9 \mathrm{Ah}$ cell at a current of $0.95 \mathrm{~A}$ corresponds to a C-rate of $1 / 2 \mathrm{C}$, which is typically shortened to $\mathrm{C} / 2$.

In the long-term, the performance of cells in practical applications is a factor of how little the capacity and the resistance changes as an interdependent function of both time and cycling.

The sheer multitude of testing variables, including cell chemistries, capacities and formats, charging and discharging profiles, testing temperature and testing set-up, makes cell comparisons based on separate experimental sets very difficult to conduct. Additionally, to the best of the authors' knowledge, an evaluation of very low-priced Li-ion cells has not been published in the literature. As a result there is a clear need for academic research comparing commercially available cells at a range of price points, with testing procedures designed to maximize the informational benefit to consumers.

In this paper we publish testing results for five types of 18650format Li-ion cells made by three different manufacturers: Panasonic, Sanyo and UltraFire (shown in Fig. 1). The testing includes initial weight, size, capacity and electrochemical impedance spectroscopy (EIS) measurements, between 40 and 80 full ageing cycles and final capacity and EIS measurements.

\section{Testing Methodology}

Experimental set-up.- The initial and final capacity testing as well as the ageing studies were conducted using a MACCOR 4000 
Table I. Initial capacities of commercial 18650-format lithium-ion batteries from literature.

\begin{tabular}{|c|c|c|c|c|c|c|}
\hline Author & Cell Type (Quantity) & Nominal Capacity & Capacity $^{\mathrm{a}}$ & Spread & @ Rate & @ Temp ${ }^{\mathrm{b}}$ \\
\hline Dubarry et $\mathrm{al}^{2}$ & Unknown(10) & $1.9 \mathrm{Ah}$ & $99.4 \%$ & $0.2 \%$ & $\mathrm{C} / 2$ & $23^{\circ} \mathrm{C}$ \\
\hline${\text { Dubarry et } \mathrm{al}^{2}}^{2}$ & Unknown(10) & $1.9 \mathrm{Ah}$ & $102.6 \%$ & $0.2 \%$ & $\mathrm{C} / 25$ & $23^{\circ} \mathrm{C}$ \\
\hline Ecker et $\mathrm{al}^{3}$ & Sanyo UR18650E (2) & $2.05 \mathrm{Ah}$ & $97.9 \%^{\mathrm{c}}$ & $1.2 \%^{\mathrm{c}}$ & $\mathrm{C} / 4$ & $35^{\circ} \mathrm{C}$ \\
\hline Mulder et $\mathrm{al}^{1}$ & Unknown $^{\mathrm{d}}(5)$ & $2.3 \mathrm{Ah}$ & $93.5 \%$ & $0.4 \%{ }^{\mathrm{e}}$ & $1 \mathrm{C}$ & $23^{\circ} \mathrm{C}$ \\
\hline Mulder et $\mathrm{al}^{1}$ & Unknown $^{\mathrm{d}}(5)$ & $2.5 \mathrm{Ah}$ & $97.2 \%$ & $1.2 \% \mathrm{e}$ & $1 \mathrm{C}$ & $23^{\circ} \mathrm{C}$ \\
\hline Reichert et $\mathrm{al}^{4}$ & A123 APR-18650-M1A & $1.1 \mathrm{Ah}$ & $102.0 \%^{\mathrm{f}}$ & $2.8 \%^{\mathrm{f}}$ & $1 \mathrm{C}$ & $20^{\circ} \mathrm{C}$ \\
\hline Stiaszny et $\mathrm{al}^{5}$ & Unknown (6) & $2.0 \mathrm{Ah}$ & $95.5 \% \mathrm{~g}$ & $\leq 1.3 \%{ }^{\mathrm{e}, \mathrm{g}}$ & $1 \mathrm{C}$ & $23^{\circ} \mathrm{C}$ \\
\hline
\end{tabular}

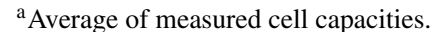

${ }^{\mathrm{b}}$ Room temperature was assumed to be equivalent to $23 \mathrm{C}$.

${ }^{\mathrm{c}}$ Approximation from the non-normalized curves in Figs. 19a, 20a, 21a and 22a of Ref. 3.

${ }^{\mathrm{d} S}$ Specified as cylindrical cells, which given the capacity are likely either 18650 or slightly larger 26650 cells.

${ }^{\mathrm{e}} \mathrm{S}$ tandard deviation value, as individual values are not published.

${ }^{\mathrm{f}}$ Approximation from the zero-cycle points in Figs. 8, 9, 14 and 15 of Ref. 4.

${ }^{\mathrm{g}}$ Approximation from the zero-cycle points in Fig. 5 of Ref. 5 .
}

Series multi-channel battery test system. Battery cells were connected using commercially available 18650 battery holders, which had their coils removed and wires replaced in order to decrease resistance. Furthermore, four-terminal sensing was used to minimize the measured voltage drop due to applied currents. The voltage measurements were taken directly from the surface of the cells, whereas the currents were applied via the upgraded holder wires. For safety purposes, cells being cycled were placed into sand-filled containers. This approach provides a heat-tolerant surface and allows any electrolyte leakage to be contained. Electrochemical impedance spectroscopy was conducted using a BioLogic VMP3 potentiostat system. The cells were connected in the same way as during the capacity testing.

The cell length was measured using a Vernier caliper with doubly folded sheets of paper used as electrical insulation on the terminals, the thickness of which was subsequently subtracted from the measurements. For measuring the diameter, a digital micrometer screw gauge was used to determine the thickest point of the cell. For most cells this point was near the positive terminal with the exception of the UltraFire $4200 \mathrm{mAh}$ cells for which it was located near the negative terminal. The weight was measured using a Mettler AE 260 Delta Range balance.

According to available manufacturer information, all cells consist of graphite anodes and cobalt-based cathodes, though the exact composition is not specified. No detailed information regarding electrolytes or separator materials was available, although it is believed that the cells all contain carbonate-based electrolytes with lithium salts. It should further be noted that there exists some uncertainty regarding various aspects of the UltraFire cells. On online marketplaces in Australia and several other countries, UltraFire-branded cells make

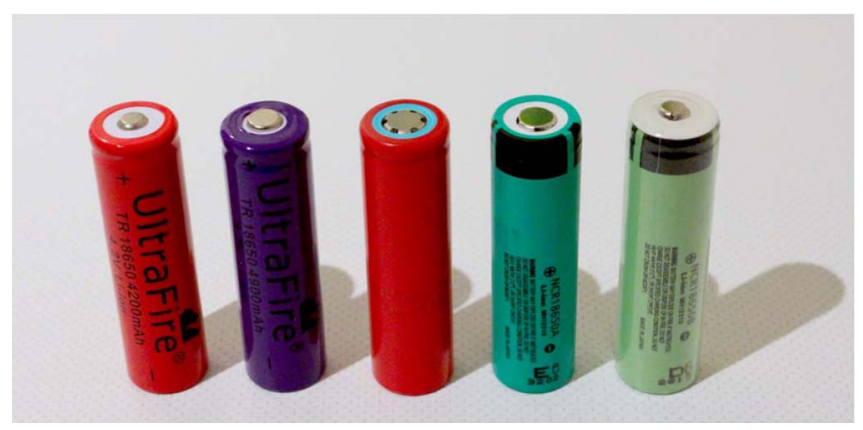

Figure 1. Tested cells, from left to right, UltraFire TR18650 $4200 \mathrm{mAh}$, UltraFire TR18650 $4900 \mathrm{mAh}$, Sanyo UR18650FM, Panasonic NCR18650A and Panasonic NCR18650B. up the majority of highly ranked search results for 18650 cells. This suggests a very high number of sales of these cells. However, a number of webpages and forum posts have suggested that manufacturers other than the company owning the right to the UltraFire brand name may have sold cells labelled as UltraFire. Furthermore, the capacity ratings notably exceed those of top-of-the-line cells from leading battery manufacturers. Given the questionable origins and capacity ratings, the UltraFire cells should be regarded as an example of a generic, low-cost products rather than a specific brand of battery cell.

Testing procedures. - The testing procedure for each cell consisted of six stages as shown in the scheme presented in Fig. 2. In the first stage the capacity of cells at beginning of life was measured over eight charges and discharges. A constant current, constant voltage (CCCV) process was applied for charging. In the first stage a constant current of $1 \mathrm{~A}$ was applied until the cells reached the maximum voltage of $4.2 \mathrm{~A}$. Once this voltage was reached, the current was progressively reduced

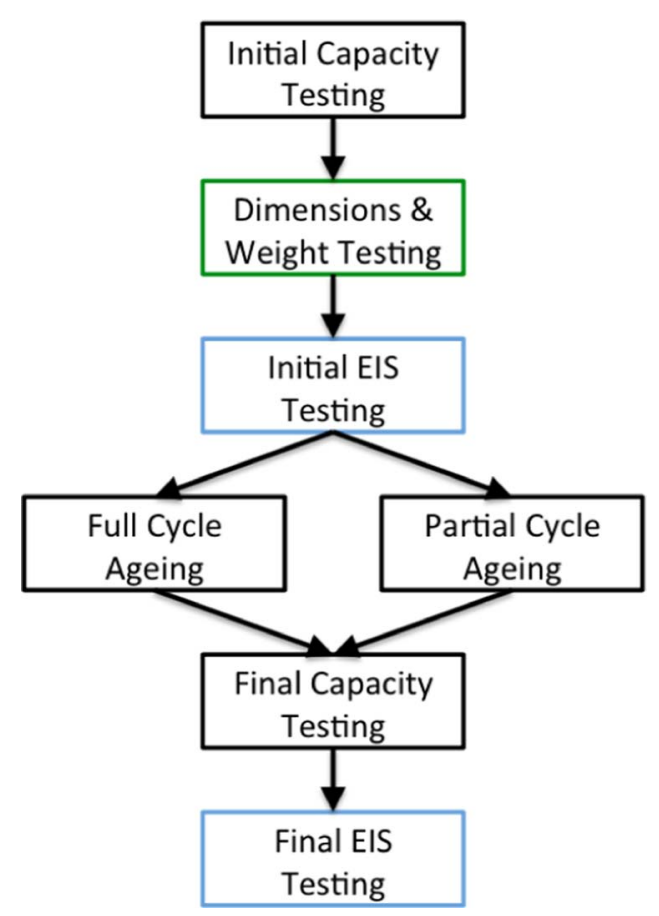

Figure 2. Schematic representation of testing procedure used in this study. 
in such a way that the terminal voltage remained equal despite further charging. When the current reached a nominal minimum value set at $50 \mathrm{~mA}$, the charging process terminated. Discharge was conducted as a pure constant current process at $1 \mathrm{~A}$. For the first five cycles all cells were discharged to $2.8 \mathrm{~V}$. For the sixth to eighth cycle, the Panasonic cells were discharged to $2.5 \mathrm{~V}$, while the remainder were discharged to the same $2.8 \mathrm{~V}$ as previously. This was done to allow comparability, while at the same time evaluating the additional capacity offered by the lower minimum limit of $2.5 \mathrm{~V}$ specified for the Panasonic cells. The approach of using CCCV for charging and CC for discharging is frequently chosen for testing as applications for batteries are frequently unable to operate with the reduced power supply that would be associated with a constant voltage discharge process.

The second stage consisted of testing focused on the dimensions and weight of the cells. This was done in order to enable comparisons of the energy density (energy per unit volume) and specific energy (energy per unit weight) between different cells. Due to the weight and size constraints in mobility applications, energy density and specific energy are among the most crucial parameters.

The third and final step of the initial testing was to conduct electrochemical impedance spectroscopy (EIS). For this testing method, alternating voltages with a range of frequencies are applied consecutively in order to determine the impedance behavior of battery cells. Based on the interesting regions identified in Ref. 6, we selected the frequency range of $0.1 \mathrm{~Hz}$ and $100 \mathrm{kHz}$.

The fourth step focused on the ageing of cells. Of the four cells of each type, two cells were underwent the same full cycles between voltage limits of 2.8 to $4.2 \mathrm{~V}$ as were used for the initial capacity tests. The two remaining cells of each type instead underwent partial cycles following the same current limits as for the full cycle test. However, for partial cycles the applied voltage was limited to a narrower range of 3.2 to $4.0 \mathrm{~V}$. To provide comparability, each tenth cycle of the partial ageing was conducted as a full cycle. This division of the ageing process into partial and full cycles was done in order to evaluate the performance of cells in certain real-life applications where full cycles are not always required and the associated increased ageing near the voltage boundaries can be avoided. To incorporate the effect of limited charging time, the constant voltage charging stage of the comparison cycles terminated when the current had either reduced to $50 \mathrm{~mA}$ or one hour of time had passed. The cycling ageing step was set to conclude after either 100 cycles, at the end of a 4-week testing period, whichever occurred first. In addition, the testing unit was set to self-terminate cycling of specific cells upon noticing errors such as loosened contact connections.
Following the cycle ageing, the cells remained at a resting state for a duration of several days to several weeks depending on when the respective cycles had concluded. Following this, the fifth stage was then to conduct a final capacity test, which was identical to the initial capacity test. The sixth and final stage of the testing was a second EIS analysis of all cells. A summary of all cells and testing conditions is shown in Table II, alongside the cell identifiers used throughout this paper.

\section{Initial Testing}

Physical dimensions and weight. - In order to compare the specific energy (energy per unit weight) and energy density (energy per unit volume) of the cells, both the physical dimensions and the weight of the cells had to be determined. Measuring the physical dimensions further provided feedback regarding how closely manufacturers were following the 18650 format, which specifies cells to have a diameter and length of $18 \mathrm{~mm}$ and $65 \mathrm{~mm}$, respectively.

The results are listed in Table III. All cells tested exceeded the format-associated diameter of $18 \mathrm{~mm}$ and all but the San 2600 cells exceeded the associated length of $65 \mathrm{~mm}$. The size increases were within provided manufacturer specification with the exception of Pan3400 cells. The latter exceeded the 18650-associated diameter and length by $3.2 \%$ and $3.6 \%$, respectively. This is a significant deviation from the standard and needs to be considered by designers of large battery packs containing as many as thousands of cells. It also has a notable impact on the energy density of the cells, which will be discussed subsequently.

Initial capacity. - Table III also shows the results of the initial testing of the cells. In the initial testing regime, the Panasonic and Sanyo cells all achieved over $93 \%$ of their listed typical charge capacity. The UltraFire cells on the other hand perform much worse, with the $4.2 \mathrm{Ah}$ and $4.9 \mathrm{Ah}$ cells only achieving $18 \%$ and $12 \%$ of their rated charge capacity, respectively. The slight differences between the rated and measured values of the Panasonic and Sanyo cells can reasonably be viewed as a product of minor variations in the applied charge and discharge cycles. In fact, according to their data sheets, the two types of Panasonic cells are rated for a minimum discharge cutoff at $2.5 \mathrm{~V}$, which was found to increase their charge capacity by a further $3 \%$. Furthermore, continuing $\mathrm{CV}$ charging to a lower current cutoff, discharging at a lower rate and discharging and conducting the charge and discharge processes at specific temperatures may well compensate for the remaining difference of $5 \%$.

Table II. Summary of cells and cycle ageing conditions.

Cell

Panasonic 3.1 Ah

Panasonic $3.1 \mathrm{Ah}$

Panasonic $3.4 \mathrm{Ah}$

Panasonic 3.4 Ah

Sanyo 2.6 Ah

Sanyo 2.6 Ah

Ultrafire $4.2 \mathrm{Ah}$

Ultrafire $4.2 \mathrm{Ah}$

Ultrafire 4.9 Ah

Ultrafire 4.9 Ah
Cycle ageing conditions (non-comparison cycles)

Identifier

Charge: $1 \mathrm{~A}$ CC-CV to $4.2 \mathrm{~V}$ until $50 \mathrm{~mA} / 1 \mathrm{~h}$ at $\mathrm{CV}$

Pan3100 (F)

Discharge: $1 \mathrm{~A} \mathrm{CC}$ to $2.8 \mathrm{~V}$

Charge: $1 \mathrm{~A} \mathrm{CC}-\mathrm{CV}$ to $4.0 \mathrm{~V}$ until $50 \mathrm{~mA} / 1 \mathrm{~h}$ at $\mathrm{CV}$

Pan3100 (P)

Discharge: $1 \mathrm{~A} \mathrm{CC}$ to $3.2 \mathrm{~V}$

Charge: $1 \mathrm{~A}$ CC-CV to $4.2 \mathrm{~V}$ until $50 \mathrm{~mA} / 1 \mathrm{~h}$ at $\mathrm{CV}$

Pan3400 (F)

Discharge: $1 \mathrm{~A} \mathrm{CC}$ to $2.8 \mathrm{~V}$

Charge: $1 \mathrm{~A} \mathrm{CC}-\mathrm{CV}$ to $4.0 \mathrm{~V}$ until $50 \mathrm{~mA} / 1 \mathrm{~h}$ at $\mathrm{CV}$

Discharge: $1 \mathrm{~A} \mathrm{CC}$ to $3.2 \mathrm{~V}$

Charge: $1 \mathrm{~A} \mathrm{CC}-\mathrm{CV}$ to $4.2 \mathrm{~V}$ until $50 \mathrm{~mA} / 1 \mathrm{~h}$ at $\mathrm{CV}$

Pan3400 (P)

Discharge: $1 \mathrm{~A} \mathrm{CC}$ to $2.8 \mathrm{~V}$

Charge: $1 \mathrm{~A} \mathrm{CC}-\mathrm{CV}$ to $4.0 \mathrm{~V}$ until $50 \mathrm{~mA} / 1 \mathrm{~h}$ at $\mathrm{CV}$

$\operatorname{San} 2600(\mathrm{~F})$

Discharge: $1 \mathrm{~A} \mathrm{CC}$ to $3.2 \mathrm{~V}$

Charge: $1 \mathrm{~A} \mathrm{CC}-\mathrm{CV}$ to $4.2 \mathrm{~V}$ until $50 \mathrm{~mA} / 1 \mathrm{~h}$ at $\mathrm{CV}$

Discharge: $1 \mathrm{~A} \mathrm{CC}$ to $2.8 \mathrm{~V}$

Charge: $1 \mathrm{~A} \mathrm{CC}-\mathrm{CV}$ to $4.0 \mathrm{~V}$ until $50 \mathrm{~mA} / 1 \mathrm{~h}$ at $\mathrm{CV}$

Discharge: $1 \mathrm{~A} \mathrm{CC}$ to $3.2 \mathrm{~V}$

Charge: $1 \mathrm{~A} \mathrm{CC}-\mathrm{CV}$ to $4.2 \mathrm{~V}$ until $50 \mathrm{~mA} / 1 \mathrm{~h}$ at $\mathrm{CV}$

Discharge: $1 \mathrm{~A} \mathrm{CC}$ to $2.8 \mathrm{~V}$

Charge: $1 \mathrm{~A} \mathrm{CC}-\mathrm{CV}$ to $4.0 \mathrm{~V}$ until $50 \mathrm{~mA} / 1 \mathrm{~h}$ at $\mathrm{CV}$

Discharge: $1 \mathrm{~A} \mathrm{CC}$ to $3.2 \mathrm{~V}$
$\operatorname{San} 2600(\mathrm{P})$

UF4200 (F)

UF4200 (P)

UF4900 (F)

UF4900 (P) 
Table III. Initial capacities and physical dimensions.

\begin{tabular}{|c|c|c|c|c|c|}
\hline & Pan3100 & Pan3400 & San2600 & UF4200 & UF4900 \\
\hline Typ. Charge Capacity (mAh) & 3070 & 3350 & 2600 & 4200 & 4900 \\
\hline Min. Charge Capacity (mAh) & 2950 & 3250 & 2500 & N/A & N/A \\
\hline Meas. Charge Capacity ${ }^{\mathrm{b}}(\mathrm{mAh})$ & $2862(2961)$ & $3166(3267)$ & 2480 & 757.1 & $579.4^{\mathrm{c}}$ \\
\hline Meas. Energy Capacity (Wh) & $10.19(10.61)$ & $11.33(11.78)$ & 9.25 & 2.74 & 1.96 \\
\hline Nominal Weight (g) & $\leq 47.5$ & $\leq 48.5$ & $\leq 48$ & N/A & N/A \\
\hline Measured Weight (g) & $\overline{4} 4.66$ & $\overline{4} 6.70$ & 45.62 & 32.24 & 37.98 \\
\hline Nominal Diameter (mm) & $\leq 18.5$ & $\leq 18.5$ & $18.3 \pm 0.2$ & N/A & N/A \\
\hline Measured Diameter ${ }^{\mathrm{e}}(\mathrm{mm})$ & $\overline{1} 8.28$ & $\overline{1} 8.57$ & 18.28 & 18.27 & 18.22 \\
\hline Specific Energy (Wh/kg) & $228.3(237.6)$ & $242.6(252.3)$ & 202.8 & 84.8 & 51.6 \\
\hline Energy Density (Wh/l) & $596.9(621.3)$ & $621.3(646.2)$ & 542.6 & 158.7 & 114.8 \\
\hline Cost per Cell (AU\$) & 11.48 & 13.48 & 5.31 & 1.45 & 1.63 \\
\hline Cost/Meas. Capacity $(\$ / k W h)$ & $1125.9(1081.8)$ & $1189.7(1144.0)$ & 574.1 & 530.1 & 831.7 \\
\hline
\end{tabular}

${ }^{a}$ Unless state otherwise, all values are an average value for four cells.

${ }^{\mathrm{b}}$ Average of first five complete discharge processes from 4.2-2.8 V; in brackets: first subsequent 4.2-2.5 V discharge processes if applicable.

${ }^{\mathrm{c}}$ Average of three cells only as fourth failed to charge or discharge.

${ }^{\mathrm{d}}$ Values for one cell only.

${ }^{\mathrm{e}}$ Measured at the thickest point, which is usually found near the positive end of the cell.

The factor of five offset between the rated and measured charge capacity of the UltraFire cells on the other hand cannot be explained by the applied cycling regime or ambient conditions. The incredible magnitude of the discrepancy, as well as the fact that the higher rated UltraFire cells performed even more poorly than the lower rated cells, casts doubt on the validity of the experimentation used to develop the ratings.

\section{Cycle Ageing}

In order to assess the impact of ageing, all cells were subjected to repetitive charge-discharge cycles following the initial testing. Of the four cells of each type, two underwent charge-discharge cycles between $2.8 \mathrm{~V}$ and $4.2 \mathrm{~V}$, described from here on as full cycles. Like the initial characterization cycles, the full cycles consisted of a constant-current, constant-voltage process with upper and lower limits as mentioned previously and a current limit of $1 \mathrm{~A}$. The cutoff current for the constant-voltage charge was chosen as $0.05 \mathrm{~A}$ (or around $1 / 50 \mathrm{C}$ for the San2600 cells which nominally have the lowest capacity).
Following each charge and discharge step, the cells rested idle for 30 minutes. Partial cycles followed the same process, with the sole difference that the lower voltage limit was set to $3.2 \mathrm{~V}$ and the upper voltage limit was set to $4.0 \mathrm{~V}$.

To provide a common basis for comparison, on every tenth cycle a special comparison cycle was run. These comparison cycles formed a basis of comparison between the cells undergoing full cycles and those undergoing partial cycles. While the comparison cycles adhered to the same voltage limits as the full cycles, the constant-voltage charging cutoff point was set as either the $0.05 \mathrm{~A}$ as for the full cycles or one hour of charging, whichever came first. This cutoff criterion was considered to be a better simulation of real-life usage in which the charging time of the battery is finite and the full constant-voltage charge may not be completed if it takes too long. An example 10-cycle segment of one cell is illustrated in Fig. 3. By comparing the amount of energy stored during the constant-voltage process, it can be seen that for the cell illustrated, the charge in the comparison cycle was terminated due to the time limit rather than the current rate limit.

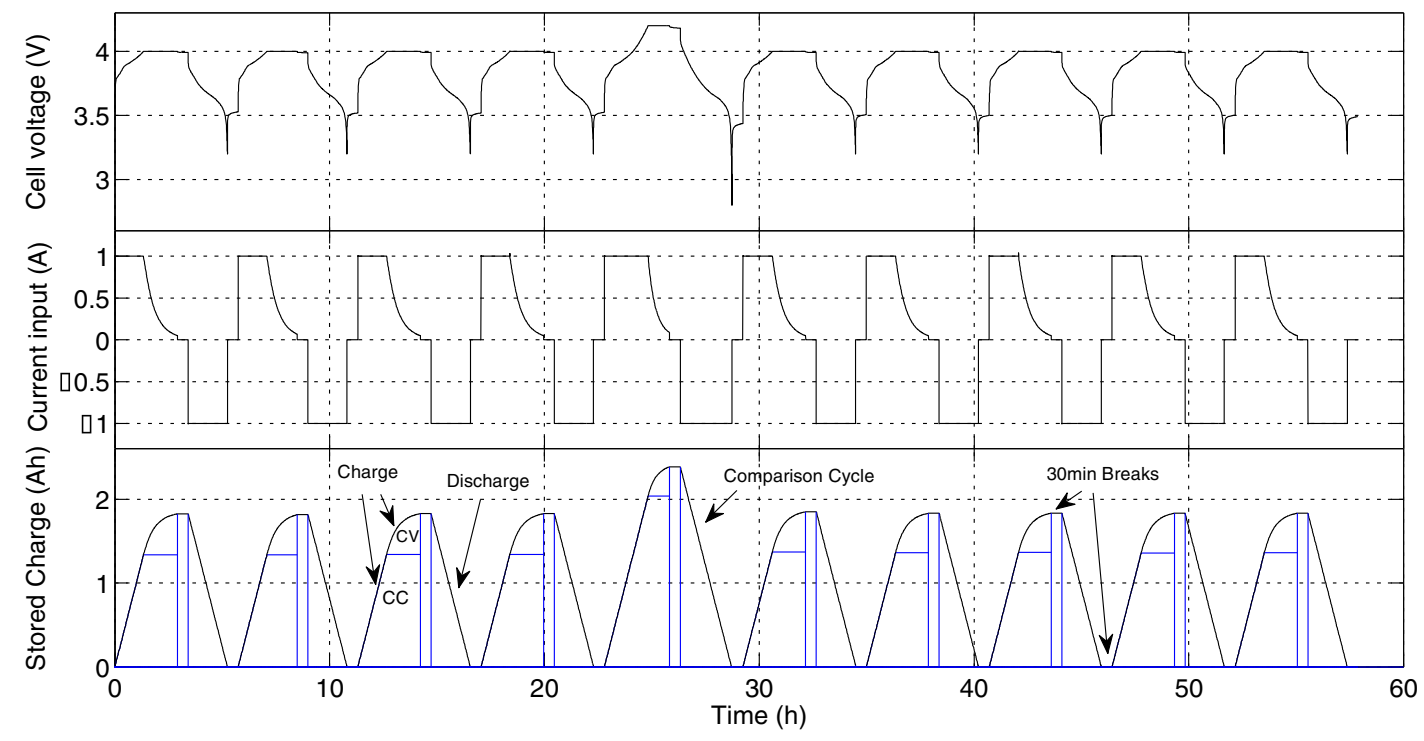

Figure 3. 10-cycle segment of the partial ageing of a Sanyo cell. Profile shows nine partial charge-discharge cycles and one comparison cycle. 


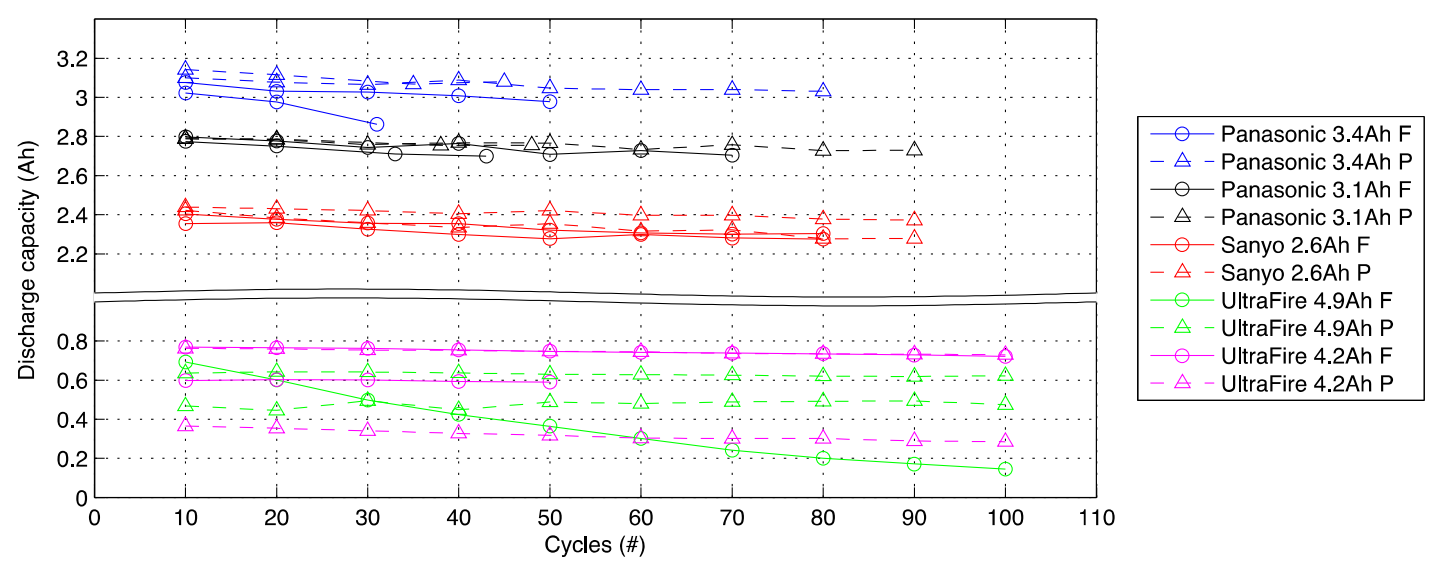

Figure 4. Cell capacity determined through the comparison cycle for cells undergoing cycling between 3.2 to $4.0 \mathrm{~V}$ (partial cycling, dashed line) and 2.8 to $4.2 \mathrm{~V}$ (full cycling, solid lines).

Full cycle ageing results. - Fig. 4 shows the capacity fade of the cells that underwent full cycles. Despite the 50-130 cycles undergone representing only a relatively small fraction of the commonly assumed Li-ion cycle life of several thousand cycles, a general ageing trend is clearly visible. While the Panasonic and Sanyo cells show a capacity decrease of only $5-10 \%$, the UltraFire cells vary much more significantly. As mentioned previously, one cell failed to charge or discharge at all. Of the remaining three UltraFire cells, two cells showed only minor decreases in capacity, while the third showed dramatic loss of $80 \%$ of the initial capacity over 100 cycles.

Partial cycle ageing.- Literature has shown that cells age especially strongly when cycled in the very high and very low SOC regions. ${ }^{3}$ As a comparison to the full cycles, partial cycles were therefore implemented, which followed the exact same protocol with the exception of using lower and upper voltage limits of 3.2 and $4.0 \mathrm{~V}$, respectively. The main goal of this testing stage was to evaluate whether a small reduction in the depth of discharge offers significant benefits in cycle life for the cells considered. This addresses the decision between buying expensive higher capacity cells to cycle partially with potentially notably higher lifespans or buying lower capacity cells with potentially lower lifespans but which can be replaced at low cost. Based on this underlying focus, the goal was to limit the increased ageing that occurs near the upper and lower bounds. The initial characterization experiments found the absolute voltage-capacity slope to be notably steeper at the end of discharge than at the end of charge. Therefore, an increase of the lower voltage limit represents less restriction in capacity compared to a similar decrease in the upper voltage limit. As a result, for partial cycles the lower limit was raised notably more than the upper limit was lowered.
Fig. 4 also shows illustrates how partially cycled cells aged as compared with fully cycled cells. For the Sanyo and Panasonic cells there is a clear trend of partially cycled cells age less with each cycle than compared to full cycles as expected. However, due to partially cycled cells absorbing and supplying less charge and energy in each cycle than fully cycled cells, a comparison on the basis of cycles is somewhat less meaningful than a comparison on the basis of cumulative energy throughput as is shown in Fig. 5.

Comparing the cells by fitting linear curves to the energy throughput measurements yields a non-conclusive result as shown in Table IV. While for both types of Panasonic cells and the UF4900 cells the partial cycles lead to a lower average degradation per energy throughput than full cycles, the San2600 and UF4200 cells find that partial cycles lead to a higher degradation. This inconsistent result suggests that the sample size of two cells per type and discharge cycle is insufficient for conclusive studies of the impact of slight cycle variations on ageing.

\section{Electrochemical Impedance Spectroscopy}

Electrochemical impedance spectroscopy (EIS) is a powerful tool to gain understanding of electrochemical processes. By recording impedance data over a wide frequency range, information about internal processes with different time constants can be ascertained. ${ }^{1}$ In recent years, a number of researchers have demonstrated the usefulness of impedance spectroscopy for lithiumion cells. A Nyquist plot of the frequency dependent impedance spectrum of a Panasonic 3.4 Ah cell is shown in Fig. 6. This data is typical of the data recorded in this study.

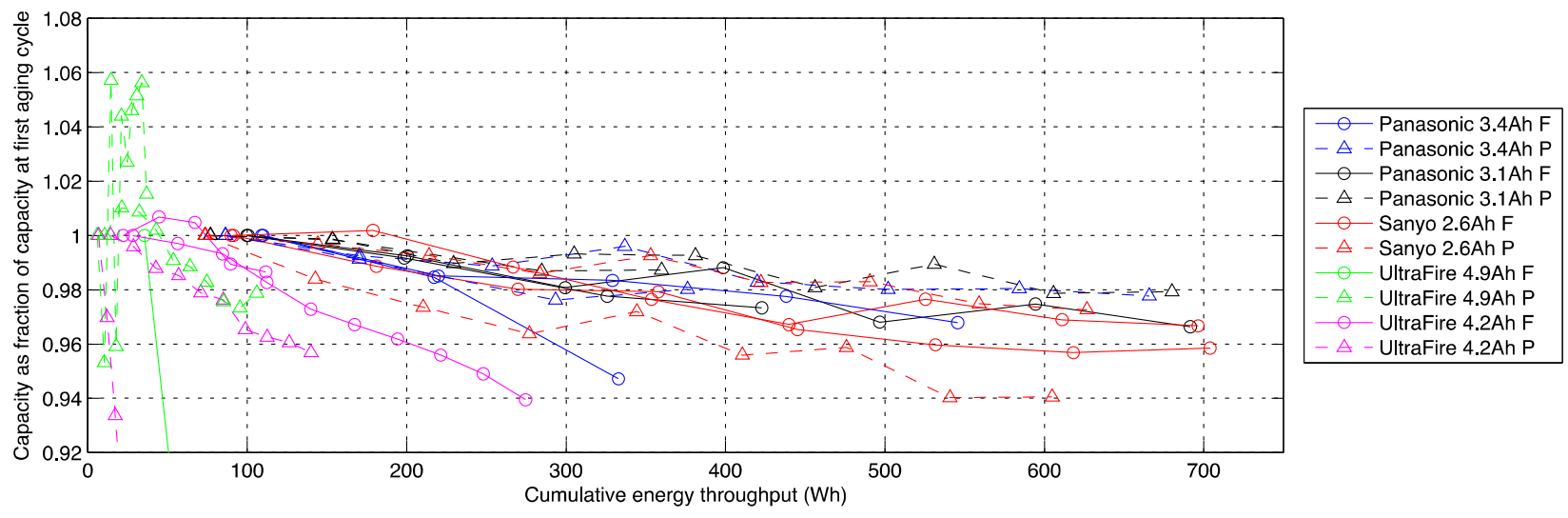

Figure 5. Fractional capacity during comparison cycles for cells undergoing partial (P, dashed lines) or full (solid lines) cycle ageing on the basis of cumulative energy throughput. 
Table IV. Average capacity reduction per unit throughput as determined from linear curve fitting.

\begin{tabular}{lcc} 
Cell Type & Cycling & $\begin{array}{c}\text { Av. Capacity Reduction per } \\
\text { 100 Wh Throughut }(\%)\end{array}$ \\
\hline Pan3100 & Partial & 0.43 \\
Pan3100 & Full & 0.7 \\
Pan3400 & Partial & 0.57 \\
Pan3400 & Full & 1.51 \\
San2600 & Partial & 0.75 \\
San2600 & Full & 0.66 \\
UF4200 & Partial & 3.71 \\
UF4200 & Full & 2.24 \\
UF4900 & Partial & 16.6 \\
UF4900 & Full & 67.9
\end{tabular}

Prior to discussing the changes in the impedance spectra of the different cells, it is useful to understand how cell connections and instrumentation affects the measurements. This is of importance, primarily due to the fact that typically lithium-ion cells are constructed to have low internal impedances. Fig. 6 also shows ten measurements of the impedance for the Pan3400 cell. Between each measurement, the cell was removed from its holder and reinserted, and after every second measurement a different battery holder was used. As shown in Fig. 6, the cell ohmic resistance at the intersection with the real axis shows a maximum variation in data of $5 \mathrm{~m} \Omega$ (ca. 10\%).

An equivalent circuit model for capturing characteristics of Li-ion cells has previously been presented by Andre et al. ${ }^{6,7}$ This circuit consists of five different regions, namely

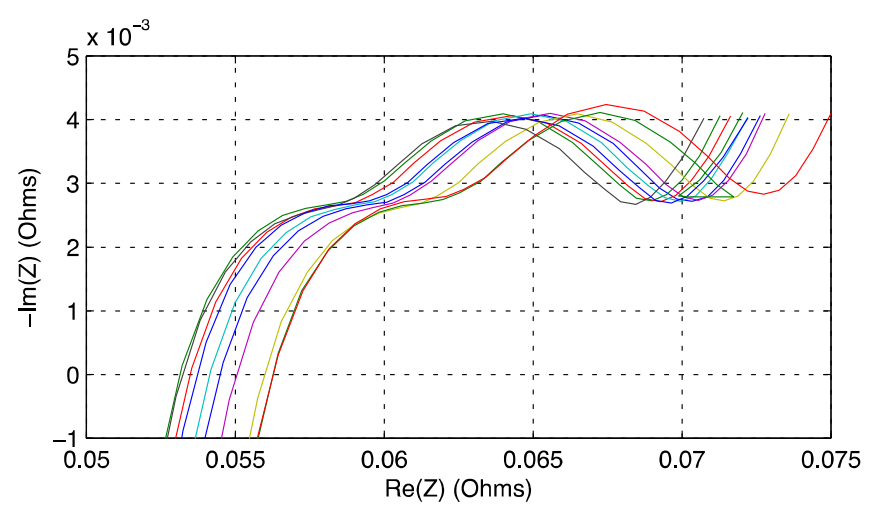

Figure 6. Measurement variations during EIS testing of a Panasonic $3.4 \mathrm{Ah}$ battery.

- Inductive reactance of metallic elements in wires and cell

- Ohmic resistance of the cell, sum of the resistances of current collectors, active material, electrolyte and separator

- Solid Electrolyte Interface resistances

- Electrode charge transfer resistance and double layer capacitance, and

- Diffusion processes within the active material

Using this equivalent circuit, all of the impedance spectra obtained for the cells were modelled. Figure 7 shows a plot of experimental vs. modelled data and the equivalent circuit, and the model output data is presented in Table V. The chi-squared $\left(\chi^{2}\right)$ minimized to below $10^{-2}$

\section{(A)}

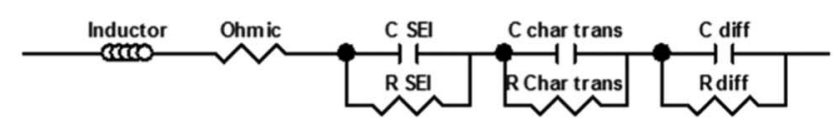

(B)
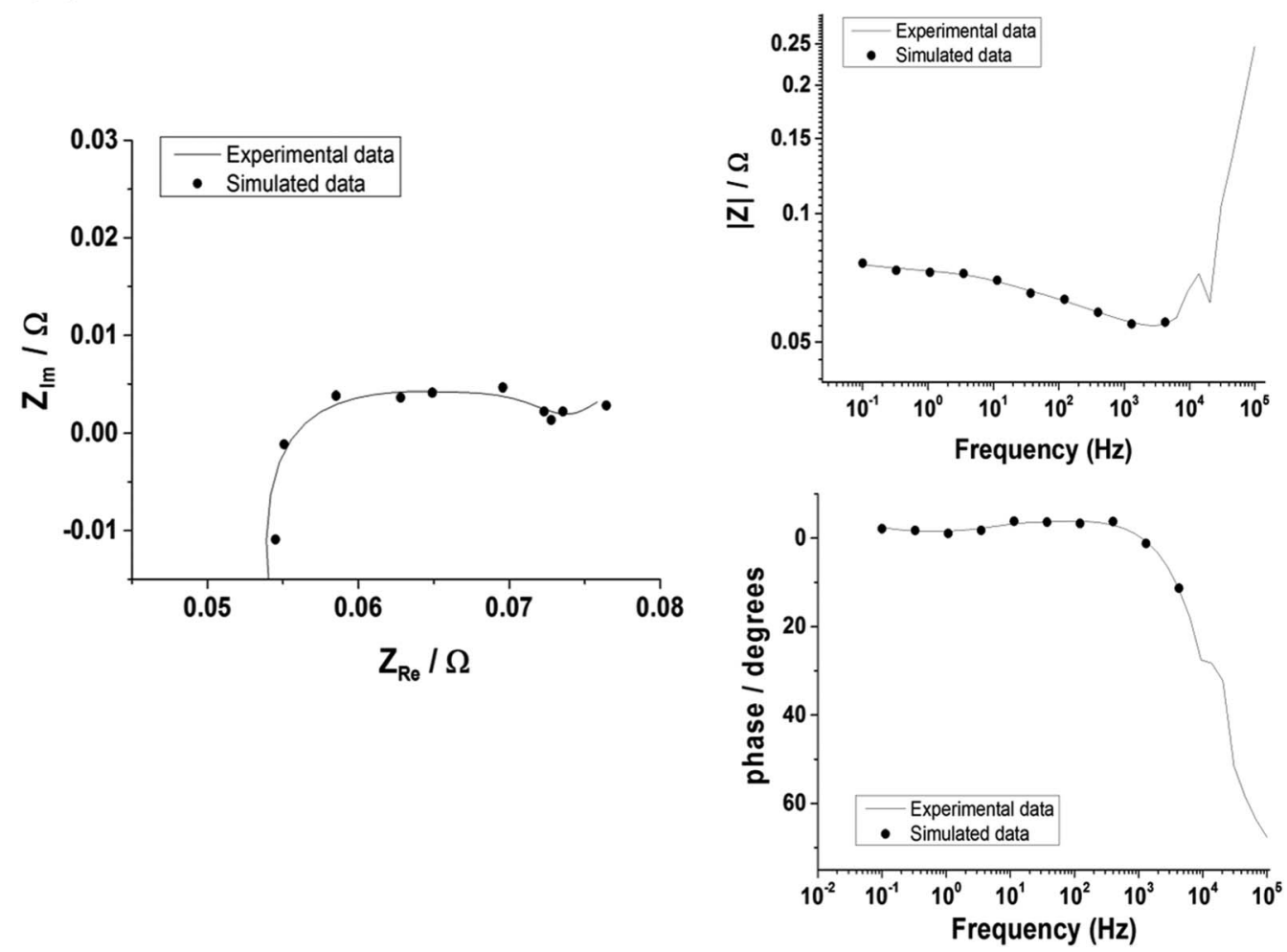

Figure 7. (A) Lithium-ion battery equivalent circuit from Refs. 6 and 7 and (B) experimental and simulated data for Panasonic 3.4 Ah cell before cycling. 
Table V. EIS model fit data for cells before and after cycling.

\begin{tabular}{|c|c|c|c|c|c|c|c|c|c|}
\hline $\begin{array}{l}\text { Cell test } \\
\text { conditions }\end{array}$ & $\begin{array}{l}\text { Inductor/ } \\
\times 10^{-7} \Omega\end{array}$ & $\begin{array}{c}\text { Ohmic } \\
\text { resistance } / \mathrm{m} \Omega\end{array}$ & $\mathrm{C} \mathrm{SEI} / \mathrm{mF}$ & $\mathrm{R} \mathrm{SEI} / \mathrm{m} \Omega$ & $\begin{array}{l}\text { C charge } \\
\text { transfer/F }\end{array}$ & $\begin{array}{c}\mathrm{R} \text { charge } \\
\operatorname{transfer} / \mathrm{m} \Omega\end{array}$ & $\begin{array}{c}\mathrm{C} \\
\text { diffusion/F }\end{array}$ & $\begin{array}{c}\mathrm{R} \\
\text { diffusion } / \mathrm{m} \Omega\end{array}$ & $\begin{array}{l}\chi^{2} \text { value/ } \\
\times 10^{-3}\end{array}$ \\
\hline \multicolumn{10}{|c|}{ Panasonic 3.1 Before cycling } \\
\hline full & 4.4 & 58 & 54 & 7.7 & 250 & 6 & 0.95 & 7.5 & 1.88 \\
\hline partial & 3.9 & 47 & 53 & 7.7 & 240 & 5.5 & 0.91 & 7.5 & 2.25 \\
\hline \multicolumn{10}{|c|}{ Panasonic 3.1 After cycling } \\
\hline full & 4.5 & 62 & 91 & 7.1 & 3.3 & 10 & 310 & 7.2 & 2.03 \\
\hline partial & 4.5 & 75 & 65 & 5.7 & 1.4 & 5.5 & 510 & 5.0 & 7.75 \\
\hline \multicolumn{10}{|c|}{ Panasonic 3.4 Before cycling } \\
\hline full & 4.5 & 52 & 51 & 8.8 & 210 & 5.6 & 1.1 & 8.5 & 2.45 \\
\hline partial & 4.6 & 55 & 52 & 9.0 & 220 & 5.8 & 1.2 & 8.8 & 2.43 \\
\hline \multicolumn{10}{|c|}{ Panasonic 3.4 After cycling } \\
\hline full & 4.4 & 55 & 63 & 7.5 & 2.8 & 9.5 & 210 & 7.8 & 2.01 \\
\hline partial & 4.3 & 75 & 65 & 8.0 & 3.1 & 9.9 & 390 & 5.0 & 2.10 \\
\hline \multicolumn{10}{|c|}{ Sanyo Before cycling } \\
\hline full & 5.9 & 56 & 50 & 7.5 & 1.7 & 14 & 0.33 & 11 & 3.06 \\
\hline partial & 6.8 & 55 & 60 & 7.6 & 2.1 & 17 & 0.43 & 11 & 3.18 \\
\hline \multicolumn{10}{|c|}{ Sanyo After cycling } \\
\hline full & 6.3 & 73 & 98 & 11 & 1.1 & 25 & 260 & 7.3 & 1.38 \\
\hline partial & 6.3 & 56 & 83 & 9.6 & 0.6 & 19 & 270 & 6.7 & 1.14 \\
\hline \multicolumn{10}{|c|}{ UltraFire 4.9 Before cycling } \\
\hline full & 5.1 & 150 & 31 & 14 & 130 & 12 & 0.29 & 25 & 1.96 \\
\hline partial & 4.6 & 400 & 32 & 15 & 110 & 12 & 0.33 & 26 & 1.36 \\
\hline \multicolumn{10}{|c|}{ UltraFire 4.9 After cycling } \\
\hline full & 4.0 & 180 & 20 & 19 & 0.26 & 27 & 41 & 18 & 2.79 \\
\hline partial & 4.2 & 320 & 34 & 18 & 0.35 & 31 & 89 & 16 & 1.90 \\
\hline \multicolumn{10}{|c|}{ UltraFire 4.2 Before cycling } \\
\hline full & 1.1 & 110 & 23 & 19 & 110 & 15 & 0.23 & 29 & 3.66 \\
\hline partial & 0.76 & 230 & 21 & 20 & 180 & 78 & 0.24 & 27 & 2.66 \\
\hline \multicolumn{10}{|c|}{ UltraFire 4.2 After cycling } \\
\hline full & 1.3 & 220 & 24 & 16 & 0.26 & 27 & 160 & 20 & 2.31 \\
\hline partial & 1.2 & 220 & 20 & 19 & 0.23 & 27 & 150 & 16 & 2.39 \\
\hline
\end{tabular}

in all cases, indicating very good agreement between data and fitted model.

Looking firstly at the Panasonic 3.1 Ah cell. Prior to cycling, the ohmic resistance for the four cells was very similar and the spread in all values close to the expected $10 \%$ variation as determined above. The Panasonic cells showed subtle differences between the pre cycling impedance and the post cycling impedance values for the ohmic resistance, SEI components and charge transfer and diffusion resistances. However, the main differences observed were related to the charge transfer capacitance, which decreased by ca. two orders of magnitude with a concomitant two orders of magnitude increase in the electrode diffusion capacitance. Based on the data presented in Table V, these trends are similar for both types of Panasonic cells. Further the data in Table $\mathrm{V}$ also shows that the effect of full or partial cycling is negligible on the EIS results.

Similar results are obtained for the Sanyo cells. However, SEI capacitance values do not change as significantly as for the Panasonic cells. In contrast to the Panasonic data, the Sanyo cells showed evidence for increase in the ohmic resistance. This is attributed to the degradation of the electrolyte during SEI formation due to a different electrolyte blend or additive component compared to the Panasonic electrolyte.

Turning to the UltraFire cells, similar trends to the Panasonic and Sanyo cells are observed. Changes in the SEI, charge transfer and electrode diffusion parameters are observed which follow the trends highlighted above. The main difference that separates the UltraFire cells from the others is the large increase in the ohmic resistance. Both the UltraFire cells have a much higher ohmic resistance, before cycling compared to the other manufacturers. Higher impedances not only reduce the energy storage efficiency of the cells but also increase the amount of heating that a given current generates. As elevated temperatures can lead to notable degradation and potential safety concerns for Li-ion cells, this is highly undesirable.

This high ohmic resistance explains the cause of the poor discharge capacity of the UltraFire cells compared to the other manufacturers and also the poor cycling ability. The ohmic resistance is attributed to the cell components: electrolyte, current collectors, separators and active material. The SEI, charge transfer and diffusion components of the impedance model would suggest that that the active material is behaving in a similar fashion to the Panasonic and Sanyo materials. Thus, the poor performance of the UltraFire cells can be attributed to cell components such as worse quality electrolyte blends or more resistive separators.

\section{Differential Capacity Analysis}

To gain an even deeper insight regarding the cell behavior before and after cycling, a differential capacity analysis of the cycling data was conducted.

Figure 8 shows the differential capacity plots for all the cells during the second cycle at $1 \mathrm{~A}$, corresponding to between $0.2 \mathrm{C}$ and $0.38 \mathrm{C}$ for the respective nominal cell capacities. The differential capacity plot for the Pan3100 cell in Fig. 8a highlights several features. During charging, the two main broad peaks are found at $3.71 \mathrm{~V}$ and $3.99 \mathrm{~V}$, with further sharp and shoulder peaks found at $3.46 \mathrm{~V}$ and $3.63 \mathrm{~V}$, respectively. Based on previous studies, ${ }^{8-11}$ these features can be attributed to chemical processes of the anode and cathode. The peaks at $3.46 \mathrm{~V}$ and $3.63 \mathrm{~V}$ can be assigned to graphite processes. The peaks at 3.71 and $3.99 \mathrm{~V}$ are linked to lithium-cobalt oxide intercalation processes. ${ }^{8,9}$ During the discharge process, 3 main peaks at $4.00 \mathrm{~V}$, $3.77 \mathrm{~V}$ and $3.48 \mathrm{~V}$ and a shoulder at $3.32 \mathrm{~V}$ are observed. The former three are attributed to $\mathrm{LiCoO}_{2}$ intercalation and ordering processes, 
(A) Panasonic 3.1Ah

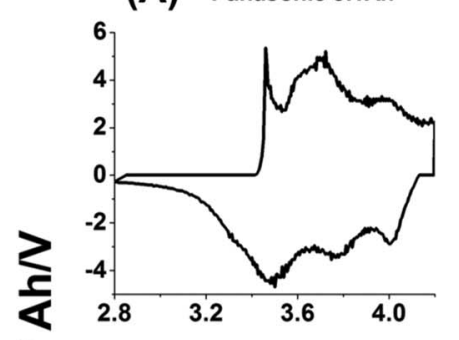

(C) Sanyo 2.6Ah

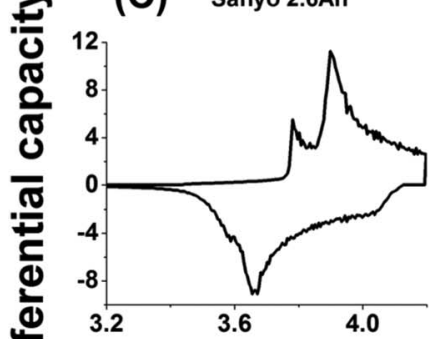

(E) UltraFire 4.9Ah

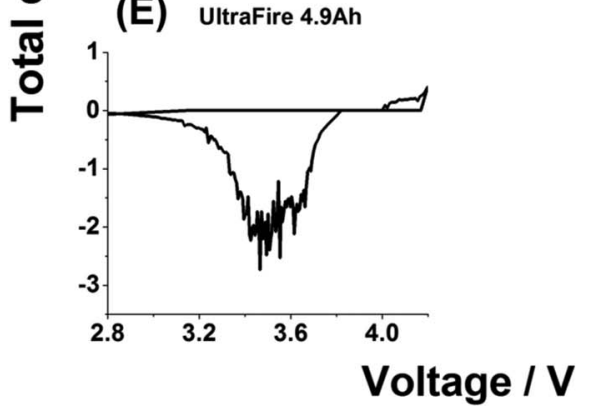

Figure 8. Differential capacity plots of all cells prior to experimental testing. A) Panasonic 3.1 Ah, B) Panasonic 3.4 Ah, C) Sanyo 2.6 Ah, d) UltraFire 4.2 $\mathrm{Ah}$ and E) UltraFire 4.9 Ah.

whereas the shoulder can be assigned to graphite. The second type of Panasonic cells, Pan3400, had a nearly identical plot (Fig. 8b) with only subtle differences of up to $\pm 0.01 \mathrm{~V}$ in some peak voltages.

The Sanyo cells display a notably different profile than both types of Panasonic cells. As illustrated in Fig. 8c, the difference is a general shift in processes, with the graphite processes now occurring at $3.78 \mathrm{~V}$ and $3.58 \mathrm{~V}$ and the $\mathrm{LiCoO}_{2}$ processes now at $3.90 \mathrm{~V}, 4.00 \mathrm{~V}$ and $3.66 \mathrm{~V}$. The EIS experiments showed that the ohmic resistance of the Sanyo cell was also slightly higher than for either type of Panasonic cells. Thus, the shifts in process voltages can be directly linked to the higher cell ohmic resistance.

In the case of the UltraFire 4.2Ah cells (Fig. 8d), the much significantly higher ohmic cell resistance caused yet a greater shift in peak process values. Indeed this effect is so pronounced that it pushes the $\mathrm{LiCoO}_{2}$ intercalation process to the edge of the cycling window. Resultantly, the primary processes identified here are due to graphite. For the second type of UltraFire cells, the UF4900, this effect is even higher, thereby resulting in little capacity during charging (Fig. 8e).

Figure 9 shows the differential capacity of all the cells following the full aging cycling tests. For both types of Panasonic cells (Figs. 9a and 9b), a very similar plot to that recorded on the first cycle is observed. Some subtle shifts in both graphite and $\mathrm{LiCoO}_{2}$ processes in the order of $\pm 0.02 \mathrm{~V}$ are observed, which can be attributed to increases in internal cell resistance. This matches with the EIS data. A small decrease in the differential capacity of ca. $0.1 \mathrm{Ah} / \mathrm{V}$ was also observed. Overall however, the Panasonic cells changed very little throughout cycling, which is consistent with the cycle ageing analysis.
(A) Panasonic 3.1Ah

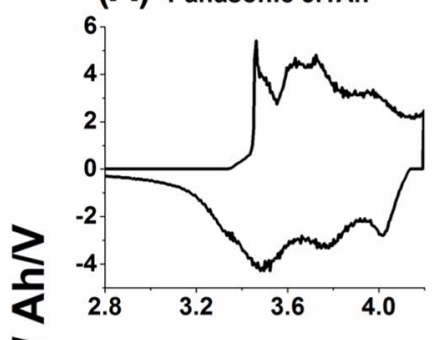

(B) Panasonic 3.4Ah

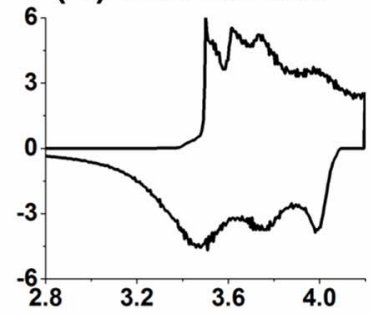

(C)

Sanyo 2.6Ah

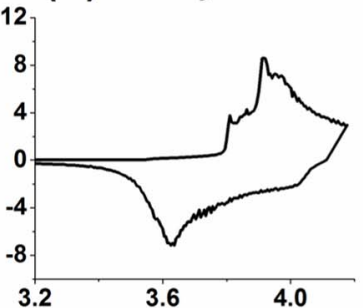

(D) UltraFire 4.2Ah

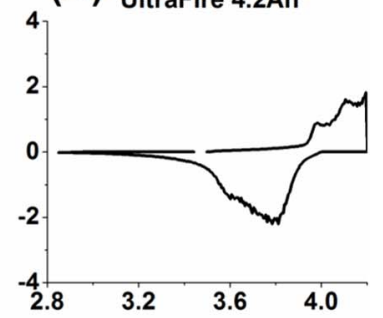

(E) UltraFire 4.9Ah

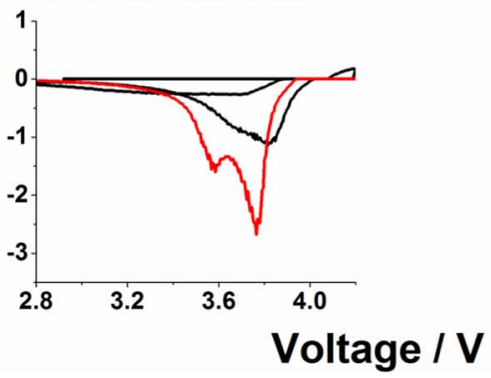

Figure 9. Differential capacity plots of all cells after full ageing cycling. A) Panasonic 3.1 Ah, B) Panasonic 3.4 Ah, C) Sanyo 2.6 Ah, d) UltraFire 4.2 Ah and E) UltraFire $4.9 \mathrm{Ah}$ (black line shows full ageing cycling and red curve is partial ageing cycling).

The Sanyo cell showed similar behavior to the Panasonic systems (Fig 9c) with small peak shifts in the order of $\pm 0.03 \mathrm{~V}$ as well as an average decrease in differential capacity magnitude of $1.9 \mathrm{Ah} / \mathrm{V}$ being observed. Clearly, the differential capacity magnitude difference is much higher then for the Panasonic cells case. However, the EIS study did show a much higher ohmic cell resistance change for the Sanyo cell. Thus, the changes in differential capacity can be attributed to the effect of higher cell resistance on the intercalation processes and chemical processes of both the graphite and the $\mathrm{LiCoO}_{2}$ materials during cycling.

For the UltraFire cells, much more significant changes were seen. For the UF4200 cells, the peak voltages change by approximately $\pm 0.05 \mathrm{~V}$. The first graphite process at $3.95 \mathrm{~V}$ showed a differential capacities decrease of $0.2 \mathrm{Ah} / \mathrm{V}$, compared to $0.6 \mathrm{Ah} / \mathrm{V}$ for the main process. During discharging, the $\mathrm{LiCoO}_{2}$ process at $3.88 \mathrm{~V}$ shows a decrease in differential capacity of $1.0 \mathrm{Ah} / \mathrm{V}$ and the graphite process $(3.61 \mathrm{~V})$ a decrease of $0.77 \mathrm{Ah} / \mathrm{V}$. For the higher rated UF4900 (Fig. 9e.), all peaks shift by around \pm 0.2 V. Furthermore, for the fully cycled cells, the differential capacity at the graphite peak at $3.82 \mathrm{~V}$ and at the $4.2 \mathrm{~V}$ limit change by $1.2 \mathrm{Ah} / \mathrm{V}$ and $0.7 \mathrm{Ah} / \mathrm{V}$, respectively. These large changes are attributed to the very large ohmic resistances observed. In addition however, we also hypothesize that the initial lack of adequate charging of the $\mathrm{LiCoO}_{2}$ material also contributes to the decrease in differential capacity because of breakdown of the anode material. It should be noted that when cycling the UF4900 cells partially (red curve in Fig. 9e) then the graphite and $\mathrm{LiCoO}_{2}$ discharging processes at 3.58 and $3.76 \mathrm{~V}$, respectively, are now detectable. This 
supports the above hypothesis, since a reduced voltage range would result in less material breakdown.

\section{Conclusions}

A testing methodology consisting of six stages of testing was proposed and conducted on five commercially available Li-ion cells. Size measurement found some cells to notably deviate from the formatassociated sizing. These variations have the potential to cause standardization and exchangeability issues and can further distort battery development trend analyses that use the format as a baseline for comparing energy densities. Initial capacity testing found that the cells from well-known manufacturers (Panasonic and Sanyo) performed to within $8 \%$ of their rated capacity. Two notably cheaper cell types sold under the UltraFire label performed much more poorly however. Out of the eight UltraFire cells tested, one cell entirely failed to accept and return charge at a rate of $1 \mathrm{~A}$, and the remaining cells on average provided less than $20 \%$ of their rated capacity. During cycle ageing of cells at $1 \mathrm{~A}$, corresponding to between 0.3 and $0.5 \mathrm{C}$, the Panasonic and Sanyo cells showed around 2-6\% degradation over an energy throughput of $700 \mathrm{Wh}$, equivalent to roughly 50-80 full cycles depending on the individual cell capacity. The lower-priced UltraFire cells performed more poorly, showing at best $6 \%$ degradation for 300 Wh of throughput and at worst more than $10 \%$ degradation after less than $30 \mathrm{Wh}$. On the basis of energy throughput, the testing did not conclusively show any difference trends in capacity degradation between cells aged using full and partial cycles, with voltage limits of 2.8-4.2 $\mathrm{V}$ and 3.2-4.0 V limits, respectively.

The electrochemical impedance spectroscopy identified the ohmic resistance as the main difference between different cells. For the Panasonic and Sanyo cells the ohmic resistance was found to be low, with a limited rise being observed throughout the cycling. In comparison, the ohmic resistance of UltraFire cells was found to be around one order of magnitude higher, which was identified as the cause for the very low cycling capacity. Other resistances for SEI layers, charge transfer processes, and diffusion processes were similar for all cells. The differential capacity analysis confirmed little material breakdown and internal resistance changes during cycling for the Panasonic and Sanyo cells. However, the UltraFire cells show significant changes in their differential capacity curves. These changes are likely partially caused by the lack of adequate charging of the cathode materials due the high internal resistance.

Overall, the comparison study shows that lithium-ion cells are far from equal, and that cell construction quality can significantly affect cell performance and lifetime. While some cells perform strongly, others are much weaker, and in extreme cases their high internal resistances can lead to complete cell failure at a very early stage.

Future work will be aimed at extending the scope of the study to take into account a wider variety of cells, as well as to determine detailed degradation mechanisms from the EIS and differential capacity data using methodologies such as presented in Ref. 12.

\section{Acknowledgments}

This work has been partially funded by the Australian Research Council via a Linkage Grant.

\section{References}

1. G. Mulder, N. Omar, S. Pauwels, M. Meeus, F. Leemans, B. Verbrugge, W. De Nijs, P. Van den Bossche, D. Six, and J. Van Mierlo, Comparison of commercial battery cells in relation to material properties, Electrochimica Acta 87, 473 (2013).

2. M. Dubarry, C. Truchot, M. Cugnet, B. Y. Liaw, K. Gering, S. Sazhin, D. Jamison, and C. Michelbacher, Evaluation of commercial lithium-ion cells based on composite positive electrode for plug-in hybrid electric vehicle applications. Part I: Initial characterizations, Journal of Power Sources 196, 10328 (2011).

3. M. Ecker, N. Nieto, S. Kbitz, J. Schmalstieg, H. Blanke, A. Warnecke, and D. U. Sauer, Calendar and cycle life study of $\mathrm{Li}(\mathrm{NiMnCo}) \mathrm{O}_{2}$-based 18650 lithiumion batteries, Journal of Power Sources 248, 839 (2014).

4. M. Reichert, D. Andre, A. Rösmann, P. Janssen, H.-G. Bremes, D. Sauer, S. Passerini, and $\mathrm{M}$. Winter, Influence of relaxation time on the lifetime of commercial lithium-ion cells, Journal of Power Sources 239, 45 (2013).

5. B. Stiaszny, J. C. Ziegler, E. E. Krau, J. P. Schmidt, and E. Ivers-Tiffe, Electrochemical characterization and post-mortem analysis of aged $\mathrm{LiMn}_{2} \mathrm{O}_{4} \mathrm{Li}\left(\mathrm{Ni}_{0.5} \mathrm{Mn}_{0.3} \mathrm{Co}_{0.2}\right) \mathrm{O}_{2}$ /graphite lithium ion batteries. Part I: Cycle aging, Journal of Power Sources 251, 439 (2014).

6. D. Andre, M. Meiler, K. Steiner, C. Wimmer, T. Soczka-Guth, and D. Sauer, Characterization of high-power lithium-ion batteries by electrochemical impedance spectroscopy. I. Experimental investigation, Journal of Power Sources 196, 5334 (2011).

7. D. Andre, M. Meiler, K. Steiner, H. Walz, T. Soczka-Guth, and D. Sauer, Characterization of high-power lithium-ion batteries by electrochemical impedance spectroscopy. II. Modelling, Journal of Power Sources 196, 5349 (2011).

8. J. N. Reimers and J. R. Dahn, Electrochemical and in situ X-ray diffraction studies of lithium intercalation in $\mathrm{LixCoO}_{2}$, Journal of the Electrochemical Society, 139, 2091 (1992).

9. J. Barker, R. Pynenburg, R. Koksbang, and M. Y. Saidi, An electrochemical investigation into the lithium insertion properties of $\mathrm{Li}_{\mathrm{x}} \mathrm{CoO}_{2}$, Electrochimica Acta 41, 2481 (1996).

10. E. M. Krieger, J. Cannarella, and C. B. Arnold, A comparison of lead-acid and lithium-based battery behavior and capacity fade in off-grid renewable charging applications, Energy 60, 492 (2013).

11. G. Ning, B. Haran, and B. N. Popov, Capacity fade study of lithium-ion batteries cycled at high discharge rates, Journal of Power Sources 117, 160 (2003).

12. M. Dubarry, C. Truchot, and B. Y. Liaw, Synthesize battery degradation modes via a diagnostic and prognostic model, Journal of Power Sources 219, 204 (2012). 